\title{
SOCIABILIDADE E ALTEROFOBIA: UM ENSAIO FILOSÓFICO
}

[Sociability and Alterophobia: A Philosophical Essay]

\section{Francisco Jozivan Guedes de Lima*}

Resumo: A filosofia contemporânea tem investigado variadas temáticas como linguagem, epistemologia social, justiça, estética, dialética, revisitado temas vinculados à metafísica, mas pouco tem discutido um tema simultaneamente especulativo e prático e, consequentemente, tão essencial para os rumos da sociedade atual: a sociabilidade. Na contramão desta tendência, este ensaio pretende abordar o problema da sociabilidade de um ponto de vista filosófico defendendo a tese que o mundo atual sofre de um déficit de intersubjetividade, algo que estes estudos cognomina de "alterofobia".

Palavras-chave: Alterofobia. Filosofia. Intersubjetividade. Sociabilidade.

Abstract: Contemporary philosophy has investigated various themes such as language, social epistemology, justice, aesthetics, dialectics, revisited issues of metaphysic, but little has discussed an issue speculative and practical and therefore as essential to the direction of current society: the sociability. Contrary to this trend, this essay aims to approach the problem of sociability from a philosophical point of view defending the thesis that the world today suffers from a deficit of intersubjectivity, something which these studies call "alterophobia".

Keywords: Alterophobia. Philosophy. Intersubjectivity. Sociability.

\footnotetext{
* Doutorando em Filosofia pela Pontifícia Universidade Católica do Rio Grande do Sul (PUCRS). Jozivan2008guedes@gmail.com
} 


\section{Introdução}

A sociabilidade é, sem sombra de dúvidas, um tema complexo e desafiante. Não se sabe se ela é uma inclinação natural humana - (concepção naturalizada das relações intersubjetivas) -, se é apreendida gradativamente a partir dos processos interativos de convivência (concepção interacionista), ou se é algo forjado a partir da criação de normas de convivência objetivando a superação da violência (concepção contratualista ou normativista das relações intersubjetivas).

Aristóteles, por exemplo, defendeu a tese que "o homem é naturalmente feito para a sociedade política"1, apontando, assim, a sociabilidade como uma propensão natural. Para ele, só os deuses e os animais prescindem dos ciclos de socialização. Já Hobbes, em sentido oposto, defendeu de modo veemente a tese que o homem é por natureza um ser egoísta e tendente ao conflito. Os homens abandonados à sua condição natural correriam o risco de destruição sendo, destarte, necessário o estabelecimento de uma condição jurídica (conditio iuris) objetivando o regramento das relações e a paz.

[...] na natureza do homem encontramos três causas principais de discórdia. Primeiro, a competição; segundo, a desconfiança; e terceiro, a glória. A primeira leva os homens a atacar os

\footnotetext{
${ }^{1}$ ARISTÓTELES. A política, p. 4. 
outros tendo em vista o lucro; a segunda, a segurança; e a terceira, a reputação ${ }^{2}$.

Se nos detivermos a observar o espírito e a dinamicidade das relações intersubjetivas atuais, parece plausível levantar a hipótese que os indivíduos no mundo hodierno sofrem de uma "alterofobia" (alter $+\phi o \beta \imath \alpha$ ), um neologismo híbrido advindo do latim e do grego que este artigo quer usar para se referir ao medo de se relacionar com o outro. A alterofobia esboçada aqui neste ensaio não tem um caráter patológico ou congênito, mas é concebida como um produto dos processos de socialização. $\mathrm{Ou}$ seja, do mesmo modo que não nascemos racistas, homofóbicos, preconceituosos, não nascemos com esse medo ou ressalva em se relacionar com o outro, mas ele é forjado e adquirido cotidianamente seja por motivos afetivos, sociais (violência), etc.

Em nível afetivo, é comum vermos pessoas frustradas por causa das feridas, das mágoas e dos ressentimentos originados de relacionamentos amorosos ou de outros tipos de relações, inclusive das mais banais possíveis. Temendo novas frustrações, bloqueiam-se, refugiam-se em si mesmas - vivem como mônadas - e passam a se entregar às relações o mínimo possível, com uma considerável dose de ressalva e desconfiança para não se ferir novamente. Em nível mais social, a violência uma mácula que também ocorre nas relações mais íntimas como é o caso da violência doméstica - faz com os indivíduos se retraiam o máximo possível, de modo que a sociedade começa a

2 HOBBES. Leviatã ou matéria, forma e poder de uma república eclesiástica e civil, p. 108. 
padecer de um comportamento coletivo pautado no medo e na insegurança.

Esse cenário tem tornado as relações sociais cada vez mais dependentes da esfera jurídica, dependência esta que se dá quando os indivíduos delegam a resolução de seus conflitos ao judiciário, às leis e aos tribunais em detrimento da dimensão dialógica e do consenso. Noutros termos, pode-se dizer de modo plausível que vivemos em tempos da involução das relações intersubjetivas e numa crescente juridificação das relações sociais $^{3}$.

Óbvio que devido à complexidade do ser humano em si mesma, é inevitável que as frustrações aconteçam, algo que comprova o quanto a vivência da sociabilidade é um desafio. $\mathrm{O}$ mais cômodo é trancar-se em si, em seus projetos, na sua imaginação, num computador e blindar-se, isto é, ficar ilhado. Todavia, isso não satisfaz as dimensões de nossa existência na sua pluralidade. Sem a sociabilidade a vida fica mais monocromática.

Nesse sentido, na contramão do individualismo corrente, este artigo se propõe a abordar filosoficamente a temática da sociabilidade tendo como ponto de partida e fio condutor de suas análises a tese que a sociedade atual carece de traços mais solidários e intersubjetivos que venham a constituir uma sociedade mais interativa, interativa não em sentido meramente virtual (Second Life), mas no seu sentido real.

\footnotetext{
${ }^{3}$ No seu livro Das Recht der Freiheit (2011), Honneth tece uma crítica a tal juridificação das relações sociais e da liberdade. Sua tese é que a liberdade não pode ser pensada como liberdade positiva (ausência de impedimentos externos), ou reflexiva (enquanto autonomia), mas como liberdade social (Soziale Freiheit), uma liberdade que tem como valor supremo ético a solidariedade. Cf. HONNETH. El derecho de la libertad: esbozo de una eticidad democrática, p. 154

ÁGORA FILOSÓFICA .v. 1. n. 2 (2014), pp. 79-95 e-ISSN 1982-999x
} 
Para cumprir seu objetivo, o artigo dispõe metodologicamente suas investigações em dois momentos: num primeiro momento trata da prioridade filosófica no tratamento da sociabilidade a partir da conexão com a temática do sentido da vida e da intersubjetividade; e num segundo momento apresenta considerações filosóficas mais pontuais sobre o tema supracitado.

\section{A prioridade da abordagem filosófica face ao problema da sociabilidade}

Inicialmente poderíamos nos perguntar sobre o porquê da primazia da filosofia no que concerne ao tratamento do tema da sociabilidade; em outros termos, o que a filosofia teria a dizer sobre o sentido da vida, especificamente, acerca da vida em seu viés intersubjetivo?

Ao tratar da relação entre filosofia e ciência, Heidegger sustenta a tese que "a filosofia é o limite da essência da ciência; a ciência deve à filosofia a sua possibilidade interna. A filosofia acha-se à base de toda ciência, mas ela não se reduz à ciência"4 Tal tese é depreendia a partir da constatação de uma tríplice crise da ciência pós-primeira-guerra, a saber, (i) crise na estrutura interna, especificamente, nos fundamentos da ciência; (ii) crise na posição da ciência no todo do ser-aí-histórico-social advinda da ruptura entre ciência e formação do caráter ético; (iii) crise da relação entre indivíduo e ciência, mormente, no que diz respeito à popularização do saber científico que na visão do próprio Heidegger seria um desfavor à ciência, haja vista as

\footnotetext{
${ }^{4}$ HEIDEGGER. Introdução à filosofia, p. 245.

ÁGORA FILOSÓFICA

.v. 1. n. 2 (2014), pp. 79-95 e-ISSN 1982-999x
} 
incompreensões e as consequentes deturpações da essência do saber científico ${ }^{5}$.

O que Heidegger quer deixar claro na sua convicção é que, na referida conjuntura do ínterim entre as duas grandes guerras mundiais, a ciência não tinha condições suficientes de tratar adequadamente o tema do sentido da vida e da sociabilidade; isso é um empreendimento que compete à filosofia porque ela está fundamentalmente entrelaçada com o tema da existência humana. Isto é, a ciência - no seu sentido mais empírico (ciências naturais / Naturwissenschaften) - não teria proposições, métodos, fundamentações e conceitos adequados para entender o humano, mas somente objetos específicos (Biologia, Química, etc.) ${ }^{6}$. O entrelaçamento entre a filosofia e o existencial - (o homem considerado em sua finitude e historicidade, o Dasein) - é posto nos seguintes termos:

Filosofamos mesmo quando não sabemos nada sobre isso, mesmo que não 'façamos filosofia'. Não filosofamos apenas vez por outra, mas de modo constante e necessário porquanto existimos como homens. Ser-aí como homem significa filosofar. $\mathrm{O}$ animal não pode filosofar; Deus não precisa filosofar. Um Deus que filosofasse não seria um Deus porque a essência da filosofia é ser uma possibilidade finita de

\footnotetext{
${ }^{5}$ Cf. HEIDEGGER. Introdução à filosofia, p. 29-42.

${ }^{6}$ Apesar de Heidegger colocar em xeque e suspeitar da força da ciência em lidar com os temas existenciais e, ipso facto, delimitá-la ao estudo do que é empírico, seu empreendimento filosófico também pode ser facilmente posto em xeque quando se tem em vista a sua adesão ao Nazismo. No mínimo, há uma incoerência e um paradoxo: de um lado um filósofo que fez sua filosofia girar em torno da existência; de outro, um indivíduo que se compromissou com um regime que exterminou milhares de humanos.
}

ÁGORA FILOSÓFICA

.v. 1. n. 2 (2014), pp. 79-95 e-ISSN 1982-999x 
um ente finito. Ser homem já significa filosofar ${ }^{7}$.

O cerne dessa citação pode ser sintetizado na seguinte tese: o filosofar é algo marcadamente antropológico; há, destarte, uma simbiose, uma articulação profunda entre o homem como um ser histórico e finito que projeta sua existência (Dasein als Entwurf) e a filosofia. O que está em jogo no ato de filosofar é a pergunta fundamental pelo sentido da existência. $\mathrm{O}$ homem tem, assim, uma "vocação profissional", não no sentido usual de profissão ligado ao mercado de trabalho, mas a incumbência de compreender sua existência. O "profissional" e o "vocacional" na língua alemã têm um sentido próximos, haja vista "Beruf" está radicado no verbo "rufen" (chamar) e, ipso facto, denotar vocação (do latim vocare).

Convém salientar que esse empreendimento filosófico da busca pelo sentido da existência não é uma tarefa unilateral do ser consigo mesmo, mas uma tarefa coextensiva aos outros e, por isso, intersubjetiva: “[...] estabelecemos em nosso ser-aí o compromisso de assumir algo como uma liderança no todo correspondente de nosso ser-um-com-o-outro (Miteinandersein)"

\section{Considerações filosóficas acerca do problema da sociabilidade}

Comumente apontamos as novas invenções tecnológicas, a exploração de outros planetas, a cura da AIDS e dos diferentes tipos de câncer, a implementação de um desenvolvimento

\footnotetext{
${ }^{7}$ HEIDEGGER. Introdução à filosofia, p. 4.

${ }^{8}$ HEIDEGGER. Introdução à filosofia, p. 7. 
sustentável que equilibre o progresso econômico-tecnológico e a preservação do meio-ambiente, dentre outros objetivos, como as grandes metas e os megas desafios do século XXI. Todavia, esquecemos ou relegamos a um plano ínfimo outro desafio que nos atinge cotidianamente, seja no trabalho, nas relações familiares, na escola, na universidade, em estádios de futebol, nas relações de vizinhança, nas relações entre culturas, etc.: o desafio da sociabilidade.

Evoluímos tecnologicamente, mas, no que diz respeito aos laços e vínculos de sociabilidade, aparentemente atrofiamos. Em 1798, em Antropologia de um ponto de vista pragmático, ao fazer a diferenciação entre "disposições técnicas" (capacidade para transformar a natureza), “disposições pragmáticas" (propensão natural à polidez e à cultura), e "disposições morais" (tendência - pelo fato de sermos racionais - à boa ação), Kant atenta para não reduzirmos a ideia de progresso tão-somente ao desenvolvimento técnico 9 . Tender ao melhor (vom Schlechten zum Bessern) também significava para ele, tornar-se mais desenvolvido moralmente e aprender a viver de forma harmoniosa em comunidade.

Apesar do Índice de Desenvolvimento Humano (IDH) pensado pelo economista indiano Amartya Sen e pelo economista paquistanês Mahbub ul Haq - contemplar aspectos importantes como educação de qualidade, expectativa de vida ao nascer e um padrão de vida decente, amiúde as grandes potências capitalistas medem o progresso baseando-se simplesmente em avanços tecnológicos e nos elevados índices de crescimento econômico, uma mentalidade rasteira que

\footnotetext{
${ }^{9}$ KANT. Antropologia de um ponto de vista pragmático, n. 326, p, 220. ÁGORA FILOSÓFICA .v. 1. n. 2 (2014), pp. 79-95 e-ISSN 1982-999x
} 
ratifica cada vez mais a contradição do capitalismo: de um lado, altas tecnologias e riquezas concentradas, de outro, indivíduos marginalizados que acordam e não sabem como conseguir o que comer; algo que, de saída, já denuncia o mito da globalização ou mundialização. Outro mito do processo de mundialização - que incide diretamente no tema da sociabilidade - é pensar que, pelo fato de estarmos virtualmente conectados, nos tornamos mais sociáveis.

Desde os tempos mais remotos, alguns filósofos vêm refletindo a questão da sociabilidade humana, suas diretrizes, desafios, aspectos naturais e normativos. Em As Leis, por exemplo, Platão nos oportuniza um diálogo entre o Ateniense, Clínias de Creta e Megilo de Esparta. Logo no primeiro livro, eles refletem sobre a genealogia das legislações e seu objetivo, se é a paz ou se é a guerra. O Ateniense defende a tese que a finalidade das legislações é a paz entre as cidades. Clínias pensa o oposto e, para ratificar sua tese, afirma que a paz não passa de um mero nome (concepção nominalista de paz), pois, na verdade, o que há entre cidades, entre indivíduos e no que diz respeito ao indivíduo consigo mesmo, é um permanente estado de conflito e tensão ${ }^{10}$.

Estariam, de fato, o universo e os indivíduos condenados à antítese e a uma permanente relação de antagonismo? A sociabilidade seria um mero produto de processos moralizadores mediante instituições religiosas e educacionais? Em que medida se justificaria falar em um processo dialético nas relações? Para o filósofo e sociólogo francês Jean Baudrillard, “o universo não

\footnotetext{
${ }^{10}$ PLATÃO. Leis e Epinomis. In: Diálogos, 626d, p. 22.

ÁGORA FILOSÓFICA

.v. 1. n. 2 (2014), pp. 79-95 e-ISSN 1982-999x
} 
é dialético - está condenado aos extremos, não ao equilíbrio. Condenado ao antagonismo radical, não à reconciliação nem à síntese" $" 11$.

Somos ensinados desde a tenra idade a ficar atentos às peripécias que o outro pode nos aprontar; crianças são praticamente condicionadas a obter vantagens perante as outras em círculos de socialização (escola, recreação...) e, mesmo na universidade, ainda persiste a lógica da autorreferencialidade, aquela que me diz que devo me formar para comprar meu carro, minha casa e realizar outros tipos de egocentrismos.

É bem possível que dos quatro pilares da educação para o século XXI propostos à UNESCO por Jacques Delors e demais colaboradores que compuseram o projeto, a saber, o aprender a ser, aprender a conhecer, aprender a fazer e o aprender a conviver, o último tenha sido pouco levado a sério e aperfeiçoado em instituições educacionais. Temos, sobretudo, atendido às demandas do capitalismo (formação técnicoprofissional para o mercado de trabalho e para a manutenção do sistema), mas escassamente investimos na dimensão da solidariedade, da formação cidadã e da sociabilidade. Dentre outras consequências desse esvaziamento da dimensão dialógica, temos um mundo cada vez mais hiperinflacionado juridicamente onde tudo parece ser resolvido tão-somente sob a égide da lei, o que resulta numa sociedade altamente positivista, isto é, legalista.

Estamos num mundo regrado e amarrado ao individualismo e com alguns resquícios de coletivismo, sociabilidade e solidariedade. Para o filósofo francês Allain

\footnotetext{
${ }^{11}$ BAUDRILLARD. As estratégias fatais, p. 9. 
Badiou, nosso mundo é contrário à aposta, ao risco, às relações espontâneas; ele é obcecado por segurança, de modo que cada um deve frequentemente calcular o que diz, o que pensa, com quem estabelecer o mínimo contato. É, nesse sentido, "um mundo onde não devemos nos abandonar aos encontros. Um mundo onde é preciso ter uma tática de vida e onde não se deve, sobretudo, apostar sua própria existência" ${ }^{\prime 2}$. Dar-se a impressão que não há tanta diferença entre as burocracias e as barreiras que o Estado e as empresas criam, e as barreiras - verdadeiras cercas de arames farpados - que criamos como limites aos outros. Adicione-se a isso, o peso do sistema capitalista que estimula a livre concorrência e a competição desregrada em detrimento de princípios éticos. Um sistema desumano que premia os fortes e pune os fracos, relegando-os às filas da exclusão.

Vivemos em sociedades onde muitos andam armados, prontos para dar respostas que intimidem e ponham o outro no seu lugar. $\mathrm{O}$ ideal neoliberal da privacidade e da intocabilidade individual ofuscou e destruiu a suposta vocação do homem à comunitariedade $^{13}$; a isso o filósofo italiano Roberto Esposito no livro Bios chama de paradigma imunitário, isto é, a ideia tipicamente moderna que, em prol da segurança, o indivíduo está imune à vida comunitária.

\footnotetext{
${ }^{12}$ BADIOU. Para uma nova teoria do sujeito: conferências brasileiras, p. 13.

${ }^{13}$ Nos Estados Unidos da América, por exemplo, quando as pessoas querem preservar sua intocabilidade individual / privacidade, usam a expressão "I take the fifth" (eu invoco a quinta emenda), como uma forma de se reportar à Quinta Emenda da Constituição: "ninguém pode ser privado de sua vida, liberdade ou propriedade sem o devido processo legal". A privacidade é, sem sombra de dúvidas, um ganho, mas quando usada ao extremo torna-se um casulo impenetrável.
}

ÁGORA FILOSÓFICA .v. 1. n. 2 (2014), pp. 79-95 e-ISSN 1982-999x 
Reconduzida à sua raiz etimológica, a immunitas revela-se como a forma negativa, ou privativa, da communitas: se a communitas é aquela relação que, vinculando os seus membros a um objetivo de doação recíproca, põe em perigo a identidade individual, a immunitas é a condição de dispensa dessas obrigações e, por conseguinte, de defesa ante os seus esforços expropriatórios $^{14}$.

O atrofiamento da sociabilidade e a alterofobia no mundo contemporâneo também são fortalecidos pela virtualidade das redes sociais, dos jogos e bate-papos destituídos de concreticidade e mediação real. $O$ filme argentino Medianeras narra muito bem isso: dentre seus personagens há um jovem chamado Martín que vive solitariamente - com a exceção de um cão que lhe faz companhia - num cubículo em Bueno Aires. É compulsivo pelo mundo virtual; resolve praticamente tudo pela internet, incluindo a compra da sua comida. Esse filme nos deixa um ensinamento: é bem possível que o ser humano esteja perdendo em ritmo acelerado a habilidade para o contato real com o outro.

Vivemos hoje em tempos de Second Life, onde a vida real é vivenciada apenas de modo espúrio e simulado. Não é raro ouvirmos testemunhos de pessoas dizendo que têm mais de mil amigos virtuais, mas que na realidade pouco se conhecem e interagem. $\mathrm{O}$ medo do outro, adicionado ao individualismo, tem nos levado a nos trancafiar; vivemos como mônadas e átomos sem relações. O medo da frustração nas relações, seja nas

\footnotetext{
${ }^{14}$ ESPOSITO. Bios: Biopolítica e filosofia, p. 80. 
amizades, no namoro, no casamento, tem sido um bom termômetro para medir o momento pelo qual passamos.

Como dito anteriormente, uma decorrência forte do atrofiamento da sociabilidade é o que quero denominar hiperinflação do jurídico. A insegurança acerca do outro nos leva a recorrer à mediação da lei. Os laços frágeis de sociabilidade são fortalecidos pela intervenção dos contratos criando, assim, uma sociedade exageradamente formalista, contratualista. Perdemos a capacidade de confiar: emprestar e negociar, mesmo com uma pessoa mais próxima, só é possível sob o aval jurídico, através de promissórias ou de uma autenticação em cartório. Perdemos a capacidade do consenso: precisamos de um juiz que arbitre a nossa relação com o outro.

\section{Considerações finais}

Pensar o problema da sociabilidade não significa apenas conceber os vínculos interpessoais como um instrumental a serviço da eficácia dos processos organizacionais como assim, suponho, tem feito a Teoria das Relações Humanas dentro da Administração, mas, indo para além disso, pressupõe conceber a sociabilidade como uma questão central acerca da qual não podemos nos eximir de refletir e, assim, encontrar condições de pensá-la por si mesma. Isso requer uma mudança de paradigma, de modo mais específico o que irei chamar de "giro societário", um giro que deve caminhar na contramão do individualismo e do consumismo modernos.

Tal giro tem como base precípua a ressignificação das relações humanas e do sistema econômico vigente: seu desafio 
consiste em redirecionar a atividade humana para além do homo oeconomicus e, inspirando-se no filósofo alemão Jürgen Habermas de Técnica e ciência como ideologia (1968), resgatar o protagonismo da dimensão comunicativa sobreposta e diluída pela tecnocracia e por sua racionalidade tipicamente instrumental. Não se trata de uma atitude conservadora e/ou reacionária de conceber os avanços tecnológicos como diabólicos, mas de pensá-los como meios e não como fins em si mesmos.

Habermas estava cônscio que a racionalidade instrumental traz consigo um risco: a cisão entre a dimensão do trabalho e a esfera da interação e, junto consigo, a diluição da intersubjetividade, isto é, das relações interpessoais.

A nova ideologia viola assim um interesse que é inerente a uma das duas condições fundamentais da nossa existência cultural: a linguagem ou, mais exatamente, a forma da socialização e individualização determinada pela comunicação mediante a linguagem comum. [...]. A consciência tecnocrática faz desaparecer este interesse prático por detrás do interesse pela ampliação do nosso poder de disposição técnica ${ }^{15}$.

Ou seja, nos tornamos experts em dominar os instrumentais tecnológicos, mas pobres em comunicação, solidariedade e contato real com os outros. Tese verossímil a de Habermas encontra-se nos escritos do filósofo francês JeanFrançois Mattéi. No seu prisma:

\footnotetext{
${ }^{15}$ HABERMAS. Técnica e ciência como "ideologia", p. 82.

ÁGORA FILOSÓFICA .v. 1.n. 2 (2014), pp. 79-95 e-ISSN 1982-999x
} 
A propagação das Luzes, apoiada no desenvolvimento das técnicas e na generalização da industrialização, levou à desumanização total do homem contemporâneo. E o progresso da razão, tão celebrado pela própria razão, é na realidade apenas um retorno da barbárie que, cada vez mais interiorizada pelo sujeito, está a ponto de destrui-lo ${ }^{16}$.

A tese de Mattéi nos serve de alerta para termos consciência que aquilo que contemporaneamente supomos como progresso, na verdade, pode ser barbárie, visualizada cotidianamente na exclusão, na indiferença, na marginalização dos oprimidos, na violência generalizada e na diluição da sociabilidade.

Certezas acerca do que é o homem, sua origem e seu destino, situam-se num campo extremamente movediço. Se ele é um ser marcado pela sociabilidade como defendeu Aristóteles, se, noutro extremo, é um ser fundamentalmente egoísta como preceituou Hobbes, ou se, num meio termo, é um ser marcado pelo antagonismo tanto da sociabilidade quanto da insociabilidade como pensou Kant, tudo isso está aberto à discussão.

Nesse sentido, independente se defendemos que a sociabilidade é uma tendência natural do ser humano (naturalismo), ou se ela é fruto da construção social (normativismo) ou, ainda, se é algo misto, o certo é que urge refleti-la com maturidade. Ela não pode ser assunto relegado tão-somente às aulas de psicologia e aos encontros com terapeutas. Eis aí, portanto, um desafio ao nosso século XXI:

\footnotetext{
${ }^{16}$ MATTÉI. A barbárie interior: ensaio sobre o i-mundo moderno, p. 51. ÁGORA FILOSÓFICA .v. 1.n. 2 (2014), pp. 79-95 e-ISSN 1982-999x
} 
como reconstruir a sociabilidade? Para isso, não há receitas prontas, mas o enfrentamento e a tematização do problema constitui o ponto de partida necessário para o salto qualitativo; isso pressupõe a devida reflexão, debate e vivência em escolas, universidades, grupos eclesiais, em empresas e nas diferentes esferas e segmentos da sociedade civil.

\section{Referências bibliográficas}

ARISTÓTELES. A política. Trad. Roberto Leal Ferreira. $2^{\mathrm{a}}$ ed. São Paulo: Martins Fontes, 1998.

BADIOU, Alain. Para uma nova teoria do sujeito: conferências brasileiras. Trad. Emerson Xavier da Silva \& Gilda Sodré. Rio de Janeiro: Relume-Dumará, 1994.

BAUDRILLARD, Jean. As estratégias fatais. Trad. Manuela Parreira. Lisboa: Editorial Estampa, 1991.

ESPOSITO, Roberto. Bios: Biopolítica e filosofia. Trad. M. Freitas da Costa. Lisboa: Edições 70, 2010.

HABERMAS, J. Técnica e ciência como "ideologia". Trad. Artur Morão. Lisboa: Edições 70, 2006.

HEIDEGGER, Martin. Introdução à filosofia. Trad. Marco Antonio Casanova. São Paulo: Martins Fontes, 2008.

HOBBES, Thomas. Leviatã ou matéria, forma e poder de uma república eclesiástica e civil. Trad. João Paulo Monteiro, Maria Beatriz Nizza da Silva, Claudia Berliner. São Paulo: Martins Fontes, 2003. 
HONNETH, Axel. El derecho de la libertad: esbozo de una eticidad democrática. Trad. Graciela Calderón. Buenos Aires: Katz Editores, 2014.

KANT, Immanuel. Antropologia de um ponto de vista pragmático. Trad. Clélia Aparecida Martins. São Paulo: Iluminuras, 2006.

MATTÉI, Jean-François. A barbárie interior: ensaio sobre o $i$ mundo moderno. Trad. Isabel Maria Loureiro. São Paulo: UNESP, 2000.

PLATÃO. Leis e Epinomis. In: Diálogos. Trad. Carlos Alberto Nunes. Belém: Universidade Federal do Pará, 1980. 